https://doi.org/10.36105/iut.2020n32.14

\title{
LOS COLECTIVOS DE BÚSQUEDA DE DESAPARECIDOS EN POZA RICA, VERACRUZ: LAS ACCIONES CIUDADANAS FRENTE A LAS INCAPACIDADES INSTITUCIONALES ${ }^{1}$
}

COLLECTIVES IN SEARCH OF THE DISAPPEARED IN POZA RICA, VERACRUZ: CITIZEN ACTIONS AGAINST INSTITUTIONAL DISABILITIES

\author{
JuAna Luisa Ríos-Zamudio \\ Universidad Veracruzana, México \\ j1_rioszam@yahoo.com.mx
}

\section{RESUMEN:}

Este trabajo es un primer acercamiento al estudio de la problemática de los desaparecidos en Poza Rica de Hidalgo, municipio de la zona norte del estado de Veracruz. Para ello, se analiza el letargo de las tres últimas administraciones gubernamentales para brindar respuestas a las familias de los desaparecidos y contener el incremento de la violencia en la entidad, así como las estrategias y resultados de las familias a través de su organización y trabajo como colectivo de búsqueda en esa región, centrando la atención en el grupo denominado Colectivo Familiares en Búsqueda María Herrera.

\section{Palabras clave:}

Colectivos de búsqueda, desaparecidos, Veracruz, Poza Rica, violencia.

\section{ABSTRACT:}

This work is a first approach to the study of the problem of the disappeared in Poza Rica de Hidalgo, a municipality in the northern part of the state of Veracruz.

1 Este trabajo de desarrolló en el marco del proyecto exploratorio State responses to movements of relatives of victims of enforced disappearance in Mexico: the case of Veracruz. Social movements' challenges and obstacles to action/research in the area of social accountability in the justice system, patrocinado por el Accountability Research Center de la American University, y coordinado por el Dr. Alberto J. Olvera, del Instituto de Investigaciones Histórico-Sociales de la Universidad Veracruzana. 
To do this, the lethargy of the last three government administrations is analyzed to provide responses to the families of the disappeared and contain the increase in violence in the state, as well as the strategies and results of the families through their organization and work as search group in that region, focusing attention on the group called the Maria Herrera Family Search Collective.

\section{Keywords:}

Search groups, disappeared, Veracruz, Poza Rica, violence.

\section{INTRODUCCIÓN}

La entidad veracruzana es hoy una de las más violentas de México, tanto por el número de hechos delictuosos que se cometen, como por las formas con las que se realizan los mismos. Se viven en ella elevados niveles de criminalidad y se observa un grave déficit de respeto a los derechos humanos. Es la única entidad de la República en la que se han declarado dos alertas de género, una por violencia feminicida y otra por agravio comparado. Se la ubica también dentro de los diez primeros lugares de las entidades con los mayores niveles de corrupción e impunidad, y se le atribuye una cifra negra de no denuncias de delitos de hasta $94.81 \% ;^{2}$ esto es, por arriba de la media nacional. Presenta, asimismo, elevadas cifras en materia de violencia política. ${ }^{3}$ Por eso fuera poco, es considerada la entidad más peligrosa para ejercer la profesión de periodista al registrar el mayor número de atentados contra dicho gremio en los últimos 15 años; ${ }^{4}$ y es, además, una de las cinco entidades con más de un homicidio violento contra defensores de derechos humanos. ${ }^{5}$

Sin embargo, la problemática de las personas desaparecidas en Veracruz es, hoy por hoy, uno de los mayores focos rojos. La tradicional indolencia política a

\section{LE CLERCQ ORTEGA y RODRÍGUEZ SÁNCHEZ LARA (2018).}

3 De acuerdo con el Reporte de Riesgo del Atlas Político Electoral en México 2018, en los periodos electorales de 2006 a 2018, Veracruz registró 143 casos de violencia política: 108 de violencia grado 1, que implica, según la propia clasificación del organismo: "Acoso y hostigamiento, amenaza, ataque a medio de comunicación, ataque físico o material, desplazamiento forzado, intervención en comunicaciones, intimidación, privación de la libertad y violencia institucional a periodistas, servidores públicos, candidatos, precandidatos, servidores públicos, alcaldes y exalcaldes", pp. 34 y 35, eventos de violencia grado 2, que puede incluir "Asesinato, atentados, tortura y desapariciones a periodistas, servidores públicos, candidatos, precandidatos, servidores públicos, alcaldes y exalcaldes” (p. 35).

Por su parte, durante el primer trimestre de 2019, el Indicador de Violencia Política de la Consultora Especializada Etellekt ubicó a Veracruz en el segundo lugar de violencia de este tipo con cinco homicidios a políticos, apenas por debajo de Oaxaca, con seis. https://www.eluniversal.com.mx/estados/estado-el-primeroen-homicidio-de-politicos

4 De acuerdo con la organización Artículo 19, Veracruz tiene un registro de 27 atentados contra periodistas, 22 de ellos ocurridos en los últimos 8 años y 1 ya durante la presente administración gubernamental, durante 2019: https://articulo19.org/periodistasasesinados/ y https://veracruz.lasillarota.com/estados/veracruz-un-estado-letal-para-periodistas-violencia-mexico-periodismo-reporteros/316211

5 La Comisión Nacional de los Derechos Humanos reporta un registro de 46 homicidios dolosos contra defensores de derecho humanos en los últimos trece años (de 2006 a julio de 2019); 13 de estos casos ocurridos durante el primer semestre de 201. Las cinco entidades con más de un homicidio contra defensores de derechos humanos son: Chihuahua (14); Guerrero (6); Oaxaca (6); Veracruz (3), y Sinaloa (2): https://www. proceso.com.mx/588311/desde-2006-han-sido-asesinados-46-defensores-de-derechos-humanos-cndh 
las necesidades ciudadanas y los también tradicionales elevados niveles de corupción e impunidad en las esferas de los tres poderes públicos (ejecutivo, legislativo y judicial), constituyeron en su momento un escenario que facilitó la incursión de grupos del crimen organizado en la entidad. La protección en ocasiones brindada por parte de algunas autoridades a los grupos criminales, dio a estos la confianza para emplear nuevas y más crudas expresiones de violencia no sólo en las luchas sostenidas entre ellos por apropiación de los territorios (plazas), sino también de manera directa en contra de la ciudadanía común. La desaparición de personas fue un hecho que no pudo seguir negándose ante los hallazgos de fosas clandestinas en varios puntos del territorio y, de hecho, una de esas fosas, localiza en agosto de 2016, ha sido etiquetada como la más grande de América Latina, con 253 cráneos y más de 14 mil restos humanos. ${ }^{6}$

Este contexto de violencia generalizada y de incapacidades institucionales para hacer frente a la permanente escalada de violencia $y$, para atender y resolver los problemas de las familias que exigen la localización de sus familiares desaparecidos, se extiende por todo Veracruz, con especial presencia en las regiones económicamente más rentables para los grupos delictivos, como es el caso de Poza Rica de Hidalgo. No obstante, esta parte de la zona norte del estado ha escapado del interés analítico de los académicos, pese a que se le considera una de las principales puertas de entrada del crimen organizado a la entidad.

El presente trabajo es un acercamiento exploratorio para el análisis del problema de personas desaparecidas que afecta al municipio de Poza Rica, con elevados niveles de violencia y con escasas o casi nulas respuestas por parte del Estado frente a tal situación. Se analizan también las estrategias y resultados de las familias de las personas desaparecidas a través de su organización y permanente trabajo como colectivos de búsqueda. En la primera parte se presenta un breve marco contextualizador de la violencia "tradicional" en el Poza Rica de Hidalgo, y de la incursión en él de la delincuencia organizada, de sus primeros avistamientos y el control que ejercen en la actualidad varios grupos criminales.

En un segundo apartado se expone el trabajo del Colectivo Familiares en Búsqueda María Herrera, el cual, como su nombre lo indica, es organizado por las familias de los desaparecidos como medida reactiva ante la falta de resultados por parte de las autoridades. Como propuesta, se ha elaborado una primera caracterización de las principales actividades de este Colectivo, la cual consideramos puede aplicarse al análisis de las actividades de otros colectivos de la entidad o de otros estados de la República. Dicha caracterización permite mostrar la diversificación e impacto del quehacer del Colectivo, que de la denuncia de las desapariciones ha pasado a la búsqueda, localización e incluso identificación de personas reportadas, además de brindar orientación, apoyo y acompañamiento para la interposición de denuncias y seguimiento de los casos, y varias situaciones más.

6 https://www.eluniversal.com.mx/nacion/sociedad/corte-ordena-abrir-informacion-de-fosas-clandestinas-deveracruz, https:/www.forbes.com.mx/descubren-en-veracruz-la-fosa-mas-grande-de-america-latina/ 
En un tercer apartado se presenta también la labor de otra organización civil que se ha perfilado como promotora y defensora de los derechos humanos en esa región, denominada Proyecto Poza Rica 2040; cuyos integrantes buscan abonar a la causa de construir un municipio "otra vez" seguro, conforme lo que afirman, destacándose de su labor el tema del correcto registro de datos para una mejor identificación de personas.

El cuarto apartado es un análisis de las relaciones que el Colectivo María Herrera ha sostenido con las instituciones de procuración y administración de justicia a través de una mirada longitudinal a un problema que abarca ya tres periodos gubernamentales concluidos y uno en desarrollo. Finalmente, en el apartado de cierre se elaboran algunas reflexiones en torno a la necesidad de ahondar en el estudio a partir de incluir nuevos elementos al análisis.

Para el desarrollo de este trabajo se participó de manera activa en el seminario temático realizado por el coordinador del proyecto en México, Alberto J. Olvera Rivera, donde bajo su dirección los integrantes del equipo discutimos los senderemos para realizar la investigación, tanto en los aspectos contextualizadores como metodológicos. Es necesario apuntar aquí que la investigación quedó delimitada en cuanto su cierre a diciembre de 2019, por lo que excede a este escrito incluir los cambios y problemáticas suscitados para los colectivos y las autoridades frente a la actual contingencia sanitaria derivada del Covid 19, aunque se mencionan algunas cuestiones relacionadas.

Se recurrió también a las entrevistas contenidas en la base de datos Entrevistas a desaparecidos en Veracruz (2017-2019) elaborada y resguardada por el coordinador del proyecto, así como a informes y estadísticas gubernamentales, académicas y de organizaciones de la sociedad civil. No obstante, las fuentes principales aquí empleadas han sido las notas de prensa de diarios electrónicos, la observación directa a través de dos visitas in loco que se realizaron en los meses de julio y agosto de 2019, y que permitieron observar de manera directa algunos de los principales problemas y efectos de la violencia en la región y, en particular, el desarrollo de entrevistas semiestructuradas.

Durante las visitas a la región se realizaron entrevistas a expertos locales conocedores de la historia contemporánea del municipio y la región, así como a reporteros y lugareños, y hubo oportunidad de charlar también con algunas autoridades municipales; por razones obvias y por solicitud de los propios entrevistados, no se señalan nombres ni alias de ninguno de ellos. Asimismo, sostuvieron varias entrevistas con la fundadora del Colectivo Familiares en Búsqueda María Herrera y con algunas de sus integrantes, y se realizó un trabajo de acompañamiento durante ese mismo año en la marcha del 30 de agosto, Día internacional de las víctimas de desaparición forzada. De igual manera, se entrevistó al fundador y entonces presidente de Proyecto Poza Rica 2040, organización de reciente creación que está buscando abonar por una mejor identificación de las personas localizadas y otras particulares en torno al tema. 


\section{INSERCIÓN DE POZA RICA EN EL CICLO DE LA VIOLENCIA EN VERACRUZ}

Fundado en 1951, Poza Rica de Hidalgo es uno de los municipios más jóvenes del estado de Veracruz. Territorialmente, es también uno de los más pequeños, con una superficie de apenas $63.95 \mathrm{~km} 2,{ }^{7}$ que representa un $0.09 \%$ del total del Estado donde, a 2015, residían 200119 habitantes. Su origen deriva de un proceso de reivindicación de derechos de los trabajadores de la entonces joven industria petrolera, nacionalizada en a finales de la década de los treinta en el siglo $\mathrm{XX}$.

1. Tihuatlán

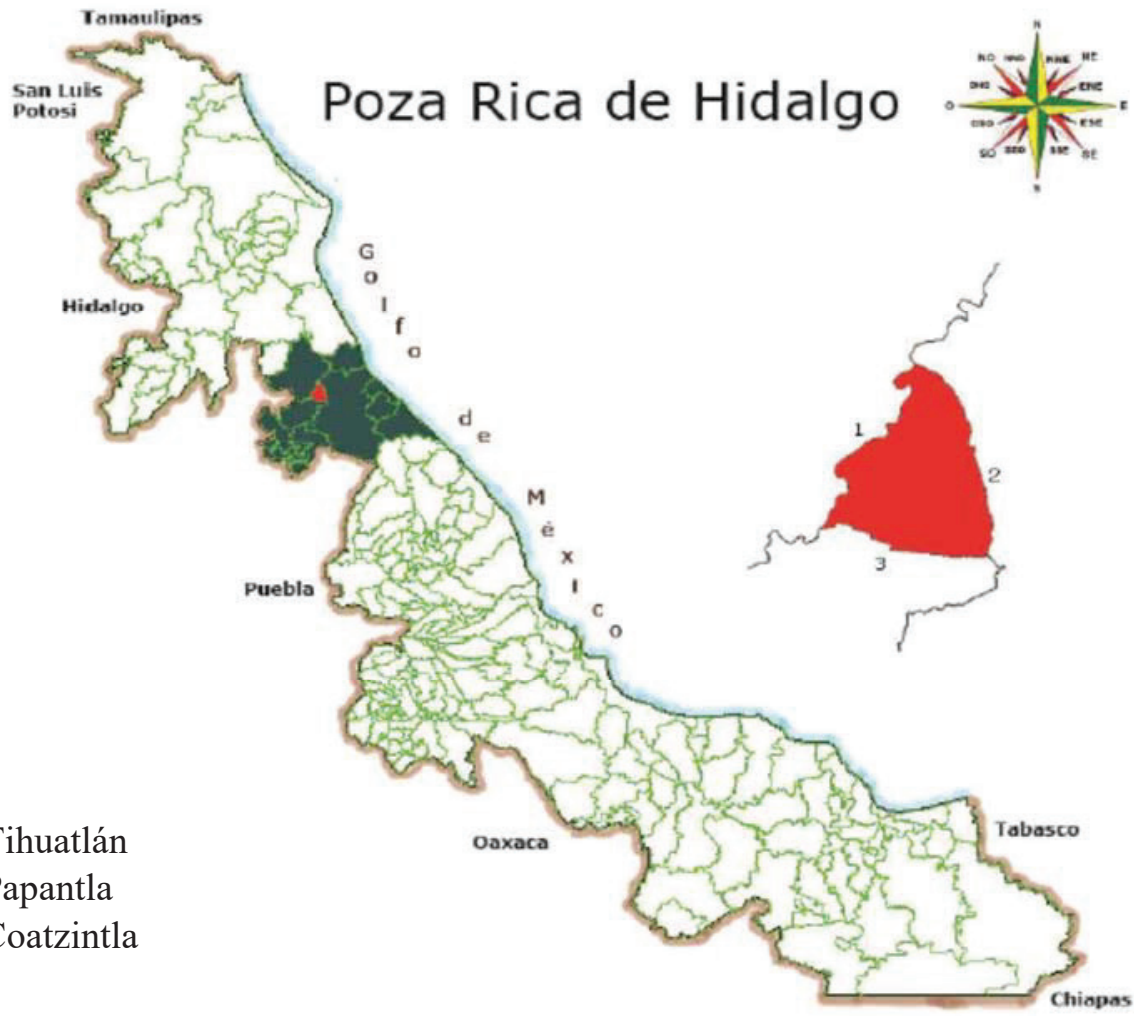

Cuadernillos municipales 2019, Gobierno del Estado de Veracruz, México, 2019.

Sus colindancias son: al norte con los municipios de Tiahuatlán, al este y al sur con Papantla, al oeste con Tihuatlán y al sur y al oeste con Coatzintla, al cual pertenecía antes de instituirse como municipio libre. Es a la fecha el principal polo económico y urbano de todos estos municipios y, junto con Cazones, integran la

7 Sistema Urbano Nacional 2018, SEGOB, 2018, p. 20. 
aglomeración Poza Rica de Hidalgo, con una población aproximada de 538000 habitantes a $2015,{ }^{8}$ lo que significa que Poza Rica concentra cerca de la mitad de la población de la aglomeración, y $85 \%$ de la población urbana se localiza en esa ciudad.

Por su grado de urbanización es considerado un municipio de muy baja marginación, ${ }^{9}$ lo que significa que cuenta con un elevado nivel de infraestructura en aspectos tales como educación, salud y vivienda con servicios básicos (agua potable, drenaje, alcantarillado y electricidad), además de contar con excelentes vías de comunicaciones y transportes y, principalmente, un elevado nivel de ocupación de su población en edad productiva. Todo esto pudo llegar a ser gracias al desarrollo de la industria petrolera que además de generar propiamente la fundación del municipio, permitió el desarrollo de una fuerte infraestructura, y que en la actualidad ayuda a mantener un alto índice de ocupación entre la población económicamente activa. No obstante, estas bonanzas se limitan a las dos zonas urbanas del municipio, que como hemos señalado son las de mayor extensión y concentran más del 80 por ciento de la población total del municipio; mientras que las zonas rurales que alcanzan las 42 localidades, continúan con serias deficiencias en cuanto a infraestructura, servicios públicos y nivel de ingresos se refiere.

Antes del ciclo de violencia desatada en la presente década, se podía considerar a Poza Rica un municipio discretamente violento. Desafortunadamente el análisis de sus procesos de violencia, en aquel y en el actual periodo, ha sido poco abordado localizándose más bien trabajos dispersos que tampoco ahondan a profundidad en los temas. Dejando de lado la violencia común, puede señalarse que las expresiones de violencia más complejas, pero toleradas $\mathrm{y}$, hasta cierto punto, socialmente consensuadas, eran entonces la violencia de género, donde destacan la violencia doméstica, y la violencia a través de la explotación sexual de niñas y jóvenes, así como la violencia gremial instruida por los líderes de la Sección 30 del Sindicato de Petróleos Mexicanos.

Durante el proceso de conformación del municipio el elevado número de trabajadores principalmente de la industria petroquímica, arribaba de manera temporal o cíclica, sin familia, y percibiendo recursos por arriba del promedio en la región y el país, generó un lucrativo mercado de sexoservicio que dio lugar actividades propiamente de trata de personas, principalmente de niñas y mujeres de entre 13 y 30 años de edad; la mayoría de las víctimas eran anteriormente trasladadas de las zonas rurales de los municipios apenas cercanos como Papantla. En la actualidad la dinámica se ha modificado en dos sentidos; por un lado, las niñas y las mujeres expuestas a estas prácticas son trasladadas ya desde municipios más alejados y de otros estados de la República, aunque también hay algunas de origen centroamericano, principalmente de El Salvador y Honduras, cuyos fenotipos resultan más atractivos a los "consumidores" de este tipo de servicios. Por otra

8 Las proyecciones de la Conapo para el municipio de Poza Rica a 2024, es de 566762 habitantes, lo que permite hablar de una tasa de crecimiento demográfico baja pero sostenida que a su vez perfila una relativa permanencia de los actuales niveles de vida entre la población.

9 A 2015, Poza Rica ocupaba el lugar número 205 de un total de 212. 
parte, las niñas y jóvenes del municipio y la región han sido también alcanzadas por esta práctica; en estos casos, luego de ser privadas de su libertad se las trasladada a otras ciudades sin posibilidades de establecer contacto con sus familiares, por lo que sus casos se reportan como de personas desaparecidas.

Por otra parte, la Sección 30 del Sindicato de Petróleos Mexicanos, instaurada desde principios de la década de los 40 del siglo XX, nutría y se nutría del poder político desde el centro que lo respaldaba, lo que bien pronto decantó a un sistema de abuso de poder y de represión hacia quienes expresaran posturas contrarias a los intereses de los líderes sindicales en turno, dando lugar a la generación de un cacicazgo gremial que periodo tras periodo imponía a las autoridades políticas municipales, y cuyo cumplimiento de los derechos colectivos de los sindicalizados eran respetados siempre y cuando se rindiera la correspondiente pleitesía, ${ }^{10}$ llegando incluso a exigir una especie de derecho de pernada o de favores sexuales a quienes pretendían ingresar a trabajar o ascender dentro de la petroquímica, sobre sí mismas en el caso de las mujeres o, para el caso de los hombres, respecto de sus hijas o esposas. Según dos de los informantes entrevistados, los problemas al interior de la organización sindical, junto con los de trata de niñas y mujeres en la región, subsisten, sólo que ahora dirigidas por los líderes delincuenciales de la plaza de Poza Rica.

Por su ubicación al norte, se considera a Poza Rica y a Pánuco como las puertas de entrada del crimen organizado proveniente del estado vecino de Tamaulipas, dejando sentir su presencia en el territorio veracruzano a finales del periodo gubernamental de Fidel Herrera Beltrán, hacia 2008. El grupo que incursiona es el llamado Cártel de los Zetas, y derivado de diversos procesos de reducción y reconfiguración de dicho grupo delincuencial la ciudad ha visto nacer mini cárteles o células de este, como es el caso de los grupos 35-Z y los Zetas Vieja Escuela. Las disputas por el territorio, igual que en otros puntos del estado, se han dado entre los Zetas y el Cártel del Golfo, el cual opera desde 2017 en la región a través de la célula denominada Fuerzas Especiales Grupo Sombra.

Si bien los eventos más aparatosos son los múltiples enfrentamientos que han sostenido ambos cárteles o sus células, las expresiones de violencia que más atemorizan a la ciudadanía son las más focalizadas hacia su persona o sus bienes y actividades, el constante despojo de sus recursos a través del secuestro, la extorsión o cobro de derecho de piso, así como los robos a mano armada. Son varios los casos de personas que han sido despojadas no sólo de sus ganancias, sino de la fuente de sus recursos: casas habitación que son inicialmente rentadas por parejas o familias "comunes" y, al cabo de apenas dos o tres meses los arrendadores se ven ante un notario público para trasmitir la propiedad del inmueble a los supuestos arrendatarios; la misma situación se ha reportado para propietarios de negocios de pequeño y mediano tamaño, y para comercios de alimentos en algunos de los cuatro mercados que tiene la ciudad, así como en casos de bares, antros y discotecas.

10 De la misma manera, el ejercicio de derechos sindicales — como préstamos de efectivo- a que tienen derecho los trabajadores sólo pueden ser ejercidos por quienes se presentan domingo a domingo en la casa del líder sindical, registra su asistencia y se toma una fotografía para hacer constar la visita. 
El gremio de taxistas también se ha visto afectado por la presencia de la delincuencia organizada, a muchos de los cuales se les obliga a pagar una respectiva cuota mensual, o a realizar traslados de personas o mercancías, o bien, a no denunciar los hechos ilícitos que se susciten a bordo de su vehículo, como es el "levantón" de personas. Este secreto a voces sobre la colusión, voluntaria o no, de algunos taxistas cobra fuerza cuando se revisa el testimonio de uno de los padres cuyo hijo taxista desapareció en 2018. Al percatarse que su hijo no regresaba a su casa, el padre acudió con el líder gremial a fin de saber si se había comunicado con él o si había salido a fuera de la ciudad por encomienda; el líder sindical lo disuadió de poner la denuncia aduciendo que ya lo estaban buscando - lo que significa que ya estaba enterado de la desaparición - y que ellos mismos, los taxistas, lo iban a encontrar porque ellos eran muchos, que no fuera al ministerio público. ${ }^{11}$

Del mismo modo, se habla de despidos injustificados o bajas en el escalafón de los miembros de la Sección 30 del Sindicato de Petróleos Mexicanos y en los mandos medianos y altos de las oficinas de la paraestatal, con el objetivo de abrir espacios para la fácil intrusión de personas pertenecientes de los grupos delictivos, en especial en las áreas referentes al manejo de gaso y oleoductos.

Al interior de las autoridades municipales es posible ver también que los intentos de intrusión pueden implicar altos costos para los funcionarios. Es el caso de Julio Roberto Christfield Torres, quien fue nombrado Director de Prevención del Delito en enero de 2018, recién iniciada la actual administración. Christfield estuvo al frente de la dirección apenas tres meses pues el 23 abril de ese mismo año fue "levantado" perdiendo toda comunicación con su familia tres días más tarde. Aunque en su momento la población desaprobó su nombramiento por considerar que su fallida carrera dentro de las instituciones de procuración de justicia se debía a sus actos de corrupción, habiendo ocupado, entre otros cargos, el de ministerio público por un breve periodo durante el gobierno de Javier Duarte, se cree que la desaparición obedeció a que intentaba traer personas ajenas al estado de Veracruz para integrar la policía municipal y así depurarla. Poco tiempo después se supo que Christfield regresó a su domicilio, pero ya no se incorporó a la dirección, al menos de manera directa. ${ }^{12}$ Dicha oficina se mantuvo acéfala por varios meses, hasta que se nombró de manera provisional a Aarón Moisés Betanzos Zumaya, cuya experiencia en la administración pública había sido como director de limpia pública en la administración anterior.

A octubre de 2019, la policía municipal de Poza Rica contaba con apenas 45 elementos, y esperaba llegar a cien para el mes de diciembre de ese mismo

$\overline{11}$ Esta entrevista fue tomada de la Base de datos señalada en la introducción de este trabajo. Un trabajo que refleja el proceso de incorporación del gremio de taxis a la delincuencia organizada lo brinda Gabriel A. Macías Zapata (2018). Si bien el estudio de Macías Zapatas está referido al caso de Cancún y su zona hotelera, en realidad, la descripción de cómo operan los grupos delictivos para "reclutar" conductores de taxis y cuáles son las consecuencias de negarse o, por el contrario, se ser demasiado leal al grupo, bien pueden considerarse formas de operar con cierto nivel de replicabilidad en otros contextos, como seguramente sucede en Poza Rica.

12 Christfield se reincorporó posteriormente como director del área jurídica de la policía municipal, donde sigue siendo señalado civilmente por malas gestiones. 
año; ${ }^{13}$ ante tal cifra el alcalde reconoció estar rebasados por la delincuencia "No es la cantidad que se requiere, faltan, y dado que los delincuentes son astutos, saben que la policía está aquí, y se van para allá, y luego la policía va para allá, y se vienen para acá, entonces es una guerra constante..." Es con este tipo de estrategias en materia de seguridad y prevención que la ciudadanía vive ahora el despertar de los grupos delictivos, pues apenas en el mes de mayo de 2019, en un vídeo de apenas 44 segundos difundido a través de redes, un grupo de hombres encapuchados denominado "Los Zetas Vieja Escuela" lanzaron un mensaje a los otros grupos criminales que venían operando en la región, así como a la población en general, para advertir dejar de apoyar a "la contra", so pena de convertirse en su objetivo para ser eliminado: "nunca nos hemos ido de la plaza, solo nos hemos estado reagrupando. Somos Los Zetas, pura guardia vieja". Respecto de este vídeo el alcalde morenista, Francisco Javier Velázquez Vallejo, no realizó declaración alguna ni solicitó apoyo como hiciera el gobernador Cuitláhuac García, para la instauración en el estado de la Guardia Nacional; y aunque sí hay presencia de esta fuerza en el municipio, la misma está dirigida a contener el robo de combustible, no a atender de manera directa la demanda ciudadana de seguridad. Actualmente toda la región del Totonacapan y la Huasteca veracruzana sigue en disputa entre células del grupo Sombra —escisión del Cártel del Golfo-, Cártel de Jalisco Nueva Generación (CJNG) y de Zetas Vieja Escuela.

$\mathrm{El}$ incremento de las incapacidades institucionales en materia de prevención del delito, pero también de las áreas de procuración y administración de justicia, conjugadas con el desinterés y falta de sensibilidad de las autoridades para siquiera reconocer la existencia de las desapariciones en Poza Rica y en la entidad veracruzana en general, dieron lugar a una impunidad tal que propició el incremento de la violencia y el crecimiento de los grupos delictivos. Esa misma parálisis de las autoridades generó también la movilización de la ciudadanía; en principio, para exigir resultados a las autoridades en el reconocimiento de las desapariciones y la búsqueda de sus familiares, para posteriormente transformarse en colectivos ya no sólo de denuncia, sino también de búsqueda de sus familiares desaparecidos y mucho más.

\section{EL COLECTIVO FAMILIARES EN BÚSQUEDA MARÍA HERRERA POZA RICA: DE LA DENUNCIA A LA BÚSQUEDA, LOCALIZACIÓN E IDENTIFICACIÓN DE PERSONAS DESAPARECIDAS}

El Colectivo Familiares en Búsqueda María Herrera Poza Rica, al igual que la mayoría de sus homólogos en otros puntos del estado y del país, es una estrategia

13 Se debe recordar que la población del municipio es de poco más de 200000 mil habitantes, y que la recomendación de Naciones Unidas es de 2 elementos por cada mil habitantes; lo que significa un déficit de más de $75 \%$ en el número de elementos de seguridad con los que debería contar este municipio; o si se quiere leer inversamente, hay en la actualidad una cobertura de apenas $25 \%$ de sus necesidades. A principios del mes de marzo de 2020 el Cabildo acordó publicar una nueva convocatoria para el reclutamiento de cincuenta nuevos miembros del cuerpo de policías, la cual fue suspendida días más tarde ante la contingencia sanitaria debida al Covid 19. 
ciudadana que va tomando forma por parte de las familias de los desaparecidos en esa ciudad para evidenciar y denunciar de las autoridades de seguridad, procuración y administración de justicia, tres aspectos concatenados: la falta de estrategias y resultados en la búsqueda y localización de personas reportadas como desaparecidas; el inadecuado registro, preservación e identificación de los cuerpos hallados en fosas clandestinas u otros sitios; y, el incremento de la violencia dada la impunidad que privilegia a los responsables de los delitos contra la vida y la libertad personal, como es el caso de las desapariciones.

El movimiento de búsqueda en Poza Rica lo inicia un pequeño grupo de padres cuyos hijos fueron desaparecidos en 2011. Se trata de los jóvenes Iván Eduardo Castillo Torres, quien entonces contaba con 17 años de edad, Pedro Galloso Hernández de 24, Jenny Isabel Jiménez Vázquez de 23 y Esmeralda Jaqueline Jiménez Estrella de 22 años y primas entre sí. Los jóvenes fueron vistos con vida por última vez el 25 de mayo de 2011 a la una de la madrugada en esa misma ciudad en un establecimiento de comida luego de asistir a la feria anual organizada por los socios de la Cámara Nacional de Comercio.

Ante la falta de resultados de las autoridades para localizar a los jóvenes, de la negativa en ocasiones para siquiera atenderles, y de la desesperación por encontrar a sus hijo, Maricel Torres Melo, madre de Iván Eduardo se organizó junto a los padres de los otros dos jóvenes desaparecidos en los mismos hechos, ${ }^{14}$ para exigir a las autoridades el cumplimiento de su labor. A su búsqueda se sumaron poco a poco otros padres en la misma situación, entre quienes figuró la señora María Elena Herrera Magdaleno, madre de cuatro personas desaparecidas: Raúl y Rafael Trijillo Herrera, desaparecidos en 2008 en Atoyac, Guerrero, y de Luis Armando y Gustavo, desaparecidos en 2010 en Poza Rica, Veracruz. Es para reconocer la labor de búsqueda y mostrar la unión y solidaridad de los demás padres, que el grupo decide dar el nombre de esta madre a la organización y registrarla así como Colectivo Familiares en Búsqueda María Herrera Poza Rica.

La resistencia por parte de algunos de los familiares de desaparecidos no fue poca; varios de los padres consideraban que los delincuentes pudieran tomar represalias y temían por la seguridad y vida de sus otros hijos. Se puede señalar que el temor era fundado no sólo porque el clima de violencia se incrementaba, sino porque los propios padres, los que iniciaron el movimiento de búsqueda, fueron también víctimas de un atentado.

Cinco años después de iniciada la búsqueda de su hija, José de Jesús Jiménez y Francisca Vázquez, padres de Jenny Isabel Jiménez Vázquez, sufrieron un atentado en junio de 2016, recién declarado el grupo como Colectivo. Estos hechos fueron reprobados por varias organizaciones nacionales e internacionales de derechos humanos. En Poza Rica, y en el estado en general, lejos de fragmentar o atemorizar a los padres, reforzaron su compromiso y determinación; para ellos y los integrantes de otros colectivos, no son los grupos delictivos los responsables

14 Los padres de Esmeralda Jacqueline se negaron desde el inicio a colaborar con los demás padres en la búsqueda de sus hijos. Posteriormente, el Colectivo obtuvo información que vinculaba a la pareja sentimental de Esmeralda Jacqueline con la desaparición de los demás jóvenes, y que ella seguía con vida. 
de estos hechos, sino las autoridades estatales. En su momento señalaron al entonces procurador del estado, Luis Ángel Bravo Contreras y a Ezequiel Castañeda Nevárez, ex subprocurador regional de justicia en Tuxpan, ya que días antes José de Jesús había dado un discurso en su presencia acusándolos de negligencia, y señalando su omisión y responsabilidad en la falta de resultados en el caso de su hija y de los otros jóvenes desaparecidos desde 2011, además de exigir a las autoridades estatales y federales, junto con otros miembros del Colectivo, una profunda investigación en el rancho La Gallera ubicado en Tihuatlán en los límites con Poza Rica. No obstante, estaba por llevarse a cabo en el estado la Segunda Brigada Nacional de Búsqueda de Personas Desaparecidas y Fosas Clandestinas liderada por Juan Carlos Trujillo Herrera, hijo de María Herrera; por lo que otros consideran que en realidad el atentado sí fue un hecho atribuible al crimen organizado a través del cual se intentó disuadir a los demás padres para que desistieran de la búsqueda de sus hijos, en particular, de la inspección a La Gallera. Lo cierto es que, desde una u otra línea posible de investigación, los responsables de los atentados siguen sin ser identificados, detenidos y procesados. Es así que Maricel Torres decidió continuar al frente del Colectivo, y buscar no sólo a Iván Eduardo, sino también a Jenny Isabel y a Pedro "estamos haciendo y seguiremos haciendo lo que las autoridades no quieren hacer" (entrevista personal).

Se suele señalar que los colectivos son en realidad agrupaciones amorfas, integrados generalmente por las madres, hermanas, tías, hijas, y algunos padres o hermanos, que más allá de su anhelo de encontrar a su familiar carecen, la más de las veces, de los conocimientos básicos en torno al marco legal, los procedimientos y los protocolos aplicables para exigir de las autoridades un adecuado desarrollo de sus actuaciones y obtener así, en la medida de lo posible, resultados efectivos para cada caso particular. En términos generales no se puede negar que, en efecto, al menos el nacimiento del Colectivo Familiares en Búsqueda María Herrera Poza Rica así fue; no obstante, la agrupación ha mantenido bastante estable el número de sus integrantes iniciales quienes, junto con otros que se han adherido posteriormente, han reconocido la necesidad de documentarse, de instruirse, de capacitarse en torno a los procesos penales y sus diversas diligencias, pero también en torno a las cuestiones forenses, de búsqueda, identificación y preservación de cuerpos.

De la información brindada en entrevistas con la directora del Colectivo, Maricel Torres, y por otras madres integrantes del mismo, así como de los datos y notas localizados en redes sociales y en páginas de diarios electrónicos, es posible realizar una caracterización inicial de las principales actividades del Colectivo, las cuales se puede decir que son: a) búsqueda; b) registro y documentación; c) inicio y seguimiento de casos; d) acompañamiento y autocuidado e) visibilización/negociación/presión política, f) capacitación, y g) apoyo a menores hijas e hijos de personas desaparecidas.

a) La búsqueda de personas reportadas como desaparecidas, debe recordarse, es la actividad inicial de todo colectivo, incluido el grupo Familiares en Búsqueda María Herrera, pues a través de esa tarea las familias esperan localizar, ya 
sea con vida o no, a su familiar reportado como desaparecido. La búsqueda se hace desde varios frentes $\mathrm{y}$, aunque pocos, se han obtenido algunos resultados.

El medio inicial y principal de búsqueda sigue siendo el rastreo de terreno; recorridos programados en lugares específicos a cielo abierto, con un variado tipo de técnicas e instrumentos en cuyo empleo han sido capacitados en temas forenses, procesales y criminalísticos por diversas organizaciones nacionales e internacionales. El Colectivo ha participado en varios rastreos en su zona de influencia y en otros estados de la República, como Guerrero y Puebla. Destaca el trabajo que han realizado desde 2017 en La Gallera, rancho ubicado en el municipio de Tihuatlán, usurpado en 2011 por elementos del Cártel de los Zetas para sus labores clandestinas. Este caso, en el que se ahonda en el último apartado de este escrito, permitió la localización de tres personas reportadas como desaparecidas, y sirvió asimismo para evidenciar a nivel nacional el desinterés del entonces fiscal Jorge Winckler y el gobernador Miguel Ángel Yunes Linares, para hacer frente y brindar la debida atención al tema de los desaparecidos, pese a haber sido un compromiso hecho durante su campaña a la gubernatura por parte de este último.

Por otra parte, las redes sociales, principalmente Facebook, han sido también empleadas por el Colectivo y sus integrantes para distribuir de manera continuada los datos de sus familiares desaparecidos, manteniéndolos en constante visibilidad para quienes consulten las páginas. Además de la información de los integrantes del colectivo, suelen distribuir también información de otros colectivos de Veracruz y de los adheridos al Movimiento por Nuestros Desaparecidos en México. De esta manera es que a través de esta labor de difusión del Colectivo se ha podido vincular hasta ahora las fotografías de más de una decena de jóvenes en condición de calle quienes habían sido reportados como desaparecidos por sus familias y estaban siendo buscados por ellas. De entre estos casos sobresale el de un joven originario del municipio de Coatzacoalcos, quien de ser un joven por arriba del promedio en sus actividades escolares, es localizado con serios problemas mentales, mismos que se atribuyen a los golpes y a la tortura a los que probablemente haya estado expuesto durante su desaparición, según lo que permiten interpretar los signos de violencia que presenta en su cuerpo.

b) El registro y documentación de casos fue una de las tareas organizativas iniciales y que, desde luego, continúa realizando el Colectivo. A cada persona que se acerca al grupo se le toman sus datos generales y los de su familiar o familiares desaparecidos. Estos datos han sido útiles para ir evaluando, en parte, los resultados de las autoridades, y comprar el trabajo que realizan entre uno y otro caso. A través de esta información también han podido establecer algunos patrones entre las personas desaparecidas, como los rangos de edad, y los modus operandi de los delincuentes, como las horas, días y calles y zonas de mayor riesgo para ser víctima de una desaparición, y si los testigos - cuando los hay - atribuyen los hechos a grupos delictivos o a alguna autoridad de seguridad.

Cierto es que en el caso de personas desaparecidas la cifra negra es aún bastante elevada, y que tampoco todos los que denuncian la desaparición de un familiar 
acude a solicitar apoyo al Colectivo o se integran a él, por lo que el registro que se lleva bien puede parecer demasiado general, escueto y parcial; no obstante, se debe recordar que esta es una labor que corresponde a las autoridades ${ }^{15}$ y que, de realizarla, tendrían más elementos para profundizar y alcanzar un determinado grado de eficacia en sus investigaciones e incluso más allá de ello, para para establecer medidas preventivas y de seguridad en la ciudad.

c) El apoyo para la presentación de la denuncia y seguimiento de casos es una labor que los propios ciudadanos le han dado al Colectivo. Al desconocer los procedimientos y, sobre todo, ante la desconfianza que tienen de las autoridades, han sido ya varias las familias que contactan primero a la directora del Colectivo solicitando su apoyo, ya sea porque así lo deciden inicialmente o porque conocidos o familiares les hacen la sugerencia. Esto ha facilitado la presentación de algunas denuncias, pues son varios los casos en los que las autoridades se niegan a recibir las denuncias, y los integrantes del Colectivo, ya instruidos varios de ellos en el desarrollo de los procedimientos, hacen una labor de presión y acompañamiento no sólo para que se les tome la denuncia, sino también para que se inicien con celeridad las primeras diligencias.

Se debe resaltar que el hecho de que los ciudadanos decidan acudir primero a solicitar el respaldo del Colectivo, habla del reconocimiento del que este goza ya la región, pues además de residentes de Poza Rica acuden a buscar el apoyo personas de los municipios vecinos, e incluso del estado vecino de Puebla.

d) El acompañamiento y autocuidado es una labor tan necesaria como cualquiera de las otras, ya que de esta manera las integrantes buscan sostenerse entre sí para continuar con la búsqueda de sus hijos y de todos los desaparecidos. "Además de lo que estás viviendo, que es no saber dónde y cómo está tu hijo, las autoridades te terminan desmoralizando con su trato, sus burlas, su falta de sensibilidad. Por eso debemos apoyarnos y hacernos fuertes", sostiene Maricel Torres.

Las varias estrategias de acompañamiento y autocuidado las han ido desarrollando de manera creativa las integrantes del Colectivo, aunque no es una tarea sencilla autosostenerse y brindar sostén al mismo tiempo. Los temas de resiliencia y autocuidado han sido poco atendidos y más bien se han llevado a cabo desde el punto de vista de la solidaridad entre personas en la misma condición para afrontar la situación de pérdida (por desaparición, secuestro u homicidio) de un familiar cercano. Entre quienes buscan a sus familiares desaparecidos están, precisamente, los que integran un colectivo y persisten en su búsqueda, reparten volantes con los rostros de sus familiares, realizan marchas y protestas, dan entrevistas, realizan búsquedas en fosas clandestinas y permanecen firmes en su objetivo. Pero también están quienes afrontan y asocian la pérdida de su familiar con la pérdida de sentido por la vida; viene así el declive de la persona y, en no pocos casos, también el de la familia. Se reportan situaciones de madres que han dejado de alimentarse perdiendo, en consecuencia, la vida; de igual manera, las

15 Sobre los problemas se hacen algunas observaciones en la parte de conclusiones y de registro María Teresa. Es de los trabajos más completos en uno de sus apartados. 
separaciones y divorcios entre parejas parece ser una constante, pues mientras uno - generalmente la madre - insiste en continuar la búsqueda, la pareja insiste para que desista de ese objetivo y se resigne a la pérdida; esto tiene especial relevancia cuando los efectos de la disputa o la separación van más allá de la pareja, que es cuando están al cuidado de hijos aún menores. No obstante, para todos todas las personas la desaparición de un familiar es igualmente dolorosa $\mathrm{y}$, aunque no en principio, la depresión y el autoabandono pueden devenir a la postre en cualquier momento, habiendo localizado el cuerpo de su familiar, por ejemplo.

e) La visibilización de la problemática de los desaparecidos y su mantenimiento en la agenda pública es otra de las actividades que llevan a cabo todos los Colectivos, asistiendo de manera sostenida y puntual a las reuniones programadas por parte de la Fiscalía General del Estado y del Gobierno del Estado; cualquiera que sea la experiencia o los resultados de reuniones anteriores, no desisten.

Para visibilizar su causa, están siempre dispuestas a dar las entrevistas a quien lo solicite. Las personas integrantes del Colectivo son personas abiertas, aunque cautas; la mayoría de las madres están ansiosas por contar su historia, dar a conocer quién o quiénes fueron sus hijas e hijos, sus gustos, sueños, y narrar cómo se los arrebataron, su incansable búsqueda, y lo poco o nada que han obtenido del quehacer de las autoridades. De igual manera, se integran de manera activa en las redes nacionales de búsqueda y participan con ahínco en las brigadas que se organizan, tanto en Veracruz como en otras entidades federativas.

Otra de las estrategias de visibilización y sostenimiento de la memoria por parte de las integrantes del Colectivo María Herrera ha sido el mantener de manera permanente las fotografías de sus hijos y familiares desaparecidos colgadas en un joven árbol de la plaza cívica frente al Palacio Municipal. El último viernes de cada mes, se reúnen a las cinco de la tarde para realizar el cambio de fotografías, ya que aunque se coloquen dentro de bolsas plásticas transparentes, se deterioran por estar a la intemperie. En silencio, desvisten y revisten nuevamente el pequeño árbol, que es el punto final de reunión durante las marchas y manifestaciones. En 2019, por cierto, durante la marcha del 30 de agosto por el Día Internacional de las Víctimas de Desapariciones Forzadas, el actual alcalde de la ciudad, a través de un representante, envió a las madres un árbol artificial de madera con hojas verdes en papel, como muestra de su solidaridad y apoyo a la causa; no obstante, no se especificó si se asumirían algunas acciones concretas y cuáles serían estas, más allá de su muestra de buena voluntad, aunque resultó curioso que una de las especificaciones que hiciera el representante del alcalde fuera que "además de facilitarles y brindarles todo el apoyo que requieran, están procurando no obstaculizar el movimiento".

f) Los cursos de capacitación en técnicas forenses han resultado de vital importancia para el Colectivo, pues, como en la mayoría de estos grupos, sus integrantes se han visto en la necesidad de ir más allá de la denuncia ante las autoridades, priorizando la búsqueda por pie propio. No obstante, para atender las necesidades y especificaciones de los procedimientos y no afectar con su actuación 
las investigaciones, han tenido que "entrenarse" a través de diversos cursos y talleres que les han brindado principalmente instituciones de la sociedad civil y académicas, tanto nacionales como internacionales. Con esta capacitación han mejorado tanto sus capacidades de búsqueda, como de resguardo y reporte de los hallazgos a las autoridades. Durante 2019, el Colectivo de Búsqueda María Herrera, gracias a las gestiones del Centro Prodh, recibió un entrenamiento de jornada completa por parte del internacionalmente reconocido Equipo Argentino de Antropología Forense, el cual estuvo enfocado en la identificación humana y búsqueda de restos. Este no es el primer taller que reciben los colectivos, y seguramente no será el último, pero es un ejemplo de cómo además de brindar apoyo, lo buscan y están por demás abiertos a recibirlo para mejorar su quehacer.

g) El apoyo a menores hijas e hijos de personas desaparecidas, es una labor que para el Colectivo es también relevante. Los menores son los que menos atención reciben por parte de las autoridades, de ahí que, acercarse a ellos y hacerles saber que sus padres están siendo buscados, resulta reconfortante en todos los casos, aunque resaltan aquellos en los que ambos, madre y padre, están desaparecidos. Como parte de esta labor, el Colectivo busca apoyar a los menos con útiles y uniformes al iniciar el ciclo escolar, así como con pequeños festejos y entrega de juguete en días "familiares" como navidad, día de reyes y día del niño.

\section{PROYECTO POZA RICA 2040: POR UN CORRECTO REGISTRO DE LOS DATOS DE IDENTIFICACIÓN DE LAS PERSONAS}

Proyecto Poza Rica 2040 (PPR 2040) es una asociación civil de promoción y defensa de derechos humanos creada de forma reciente en 2018. Toma su nombre de la Agenda para el desarrollo sostenible 2030 de Naciones Unidas, con la prospectiva para Poza Rica de que el municipio pueda alcanzar para el año 2040 los objetivos planteados por la Agenda. El capital humano de la organización es aún reducido; cuenta con siete integrantes entre contadores, administradores, arquitectos y tres abogados, estos últimos adscritos a la Barra de Abogados de Poza Rica, ${ }^{16}$ quienes dicen mantener buenas relaciones con otros compañeros del gremio, así como con algunos operadores de los sistemas de procuración y administración de justicia (principalmente del ámbito federal) y, en menor medida, de los sistemas seguridad pública.

De acuerdo con su primer presidente, el abogado Carlos Asdrúbal Pantoja de la Cruz, el objetivo de PPR 2040 es contribuir a la generación de una cultura de la seguridad, la prevención y el ejercicio de derechos entre los pozarricenses. En tal sentido, las dos líneas de acción principales han sido, por un lado, a través de los mecanismos de transparencia, exigir de las autoridades un adecuado ejercicio de sus atribuciones; ${ }^{17}$ por el otro, orientar legalmente a particulares, e incluso a algunas autoridades, en aspectos relativos a delitos que afecten la libertad de personas,

$\overline{16}$ La cual está integrada por poco más de 160 abogados.

17 La organización ha realizado varias acciones y denuncias en materia de transparencia en busca de un adecuado ejercicio de los recursos públicos. 
como es el caso de la desaparición forzada de personas, tanto en su aspecto preventivo como de atención y seguimiento de casos.

Si bien la violencia, en varias de sus expresiones ha disminuido relativamente en la región, Poza Rica continúa siendo blanco principal de los grupos delictivos y sus habitantes continúan padeciendo sus efectos, de ahí el interés de la Asociación por incluir estos temas en su agenda de trabajo. Sus integrantes consideran indispensable un tratamiento más profesional de las problemáticas en torno a los desaparecidos, ya que desde sus perspectiva los colectivos pocas veces cuentan con miembros instruidos en los procesos legales o de investigación, lo que dificulta que para cada caso puedan exigir a las autoridades apeguen su actuación a los procedimientos y protocolos establecidos en el marco legal, a fin de obtener resultados satisfactorios de búsqueda, localización e identificación de personas.

Las primeras horas de investigación resultan fundamentales para llevar a cabo las respectivas pesquisas, establecer y seguir líneas de investigación más concretas. Es en ese momento, en el periodo inicial de presentación de la denuncia, que la Asociación PPR 2040 ha centrado su atención y donde está realizando una interesante contribución. En sus primeros análisis sobre la problemática de los desaparecidos y sobre el marco legal relativo, sus abogados identificaron que los protocolos de investigación de las autoridades exigen a los ofendidos o familiares de la víctima, hagan una "correcta descripción" de la persona, y aporte los "datos correctos" para poder hacer la búsqueda y localización del familiar. Los integrantes de la organización PPR 2040 se cuestionaron sobre las probabilidades de que un ofendido o persona que presente la denuncia por este tipo de delitos proporcione los datos correctos para una rápida localización de identificación de su familiar en el estado de shock en el que generalmente se encuentra durante las primeras horas de suscitados los hechos.

La realización de una adecuada descripción de un familiar pudiera parecer una tarea simple, y hay detalles que pueden resultar fundamentales para realizar una correcta identificación de un cuerpo localizado, como un lunar u otra marca de nacimiento con cierta forma o tamaño, una cicatriz, un tatuaje, una fractura, entre muchos otros. Sin embargo, como se ha señalado, el estado de shock en el que suele encontrarse quien realiza la denuncia hace que se pasen por alto varias de estas características, realizándose descripciones demasiado generales que poco sirven para vincular el caso con el hallazgo de algún cuerpo. Esto lo comprobaron los integrantes de la Asociación a través del análisis de varios expedientes en los que se omitía informar de características que pudieran haber llevado a una más pronta localización de algunas de las personas señaladas como desaparecidas y cuyos cuerpos ya habían sido localizados, pero no identificados.

La praxis mostró, pues, que no existe una correcta descripción de las personas desaparecidas, de sus características generales y específicas y que, en ocasiones, tampoco es posible realizar comparativas de $\mathrm{ADN}$, por lo que será complicado llevar a cabo una correcta identificación de los cuerpos localizados. ${ }^{18}$

18 PPR2024 ha ayudado a identificar algunos de los cuerpos localizados en la zona. Uno de los casos que nos fue narrado se trató de la revisión que el equipo hizo sobre algunas carpetas de descripción de cuerpos 
Fue así que, estudiando y comparando las medidas implementadas en otros contextos de desapariciones sistemáticas, la organización dio con el tarjetón que durante 2006 y 2011 se implementó en Ciudad Juárez, Chihuahua para una mejor descripción de las mujeres reportadas como desaparecidas. Dicho documento, si bien era bastante escueto, fue útil para incrementar el número de recuperación de cuerpos hasta en un $60 \%$, por lo que fue tomando por la Asociación como base para el diseño de una tarjeta con el mismo objetivo.

Considerando que en el tema de protocolos de búsqueda, localización e identificación de personas se había avanzado de 2011 a la fecha, PPR 2040 se dio a la tarea de estudiar varios de esos protocolos diseñados en México y otros países, lo que les dio claridad sobre las deficiencias del tarjetón que originalmente les sirvió de guía, y también sobre la necesidad de incluir en su propio diseño otros elementos para que, con datos aún más precisos, las autoridades puedan llevar a cabo una mejor investigación, una búsqueda más adecuada y una mejor localización, $\mathrm{y}$, sobre todo, una mejor identificación.

La Tarjeta de Identificar Personal diseñada por el PPR 2040 está elaborado en cartulina opalina y tamaño oficio con información únicamente del lado frontal. Cuenta con un recuadro para colocar una fotografía del titular del documento, la cual se sugiere sea de alta resolución para que se aprecien con la mayor claridad posible las características de la persona; se sugiere también actualizar la fotografía por lo menos cada año tratándose de personas adultas, y cada seis meses cuando se trate de menores, pues en este último caso los cambios morfológicos son más rápidos. En el documento se incluye una pequeña bolsa plástica para que se integren algunas muestras de uñas o de cabellos con raíz, a fin de conservar un registro permanente de $\mathrm{ADN}$. Las secciones que abarca la tarjeta son: a) Información personal del titular del tarjetón, esto es, nombre, domicilio, fecha de nacimiento y apodo o alias; b) Características físicas: género, edad, peso, estatura, complexión, tez, ojos y registro dental; c) Características distintivas, esto es, que pudieran ser peculiares de la persona reportada como desaparecida: aretes, anteojos, lunares, tatuajes, marcas, braquets, pupilentes, ropa, calzado; d) Características comparativas: esta es la sección en la que se sugiere "engrapar" la pequeña bolsa plástica con las muestras de uñas o cabello para obtener el ADN y plasmar

localizados, pero no identificados. Llamó la atención del equipo que hubiera entre ellos un cuerpo con un tatuaje tan peculiar y que no hubiera sido identificado. Analizando algunas carpetas de investigación, se conjeturó que el cuerpo tenía similitudes con una persona a quien se reportaba como desaparecida, pero en cuya descripción no incluía dato alguno sobre un tatuaje. Al buscar a quien había interpuesto la denuncia, la madre del desaparecido, ésta reportó que, en efecto, su hijo contaba con un tatuaje de tales características, pero que había olvidado señalarlo al momento en que le brindó la descripción del mismo, porque estaba muy alterada. La identificación de este cuerpo llevó meses y se logró gracias al a iniciativa de PPR2040; no obstante, la madre había recorrido varios municipios del estado tratando de localizar a su hijo, incluso había acudido a buscarlo a varias fosas, como las de San Fernando, en Tamaulipas. Su esposo, padre del desaparecido, había tratado de persuadir a su mujer para que desistiera de su búsqueda, lo que finalmente, llevó a la separación de la pareja. El cuerpo, que yacía en una fosa común, había estado el tiempo legal (3 días) en un servicio funerario luego de su localización, tiempo durante el cual la madre ya lo buscaba. El servicio Médico Forense, al momento en que se realizó el presente estudio, no estaba activo en la región, sino que lo prestaban las funerarias. 
las huellas dactilares de los cincos dedos de ambas manos; e) Redes sociales: se recaban aquí las principales redes sociales (Twitter, Instagram, WhatsApp, Facebook) que el titular de la tarjeta suele ocupar a fin de obtener información para su localización identificando posibles líneas de investigación a seguir, y, finalmente, f) Nombre, teléfono y domicilio de la persona con quien establecer contacto en caso de localización (Véase ANEXO A.1).

Luego de su elaboración, la siguiente tarea de la Asociación ha consistido generar estrategias para la distribución del tarjetón tanto entre los pozarricenses como entre ciudadanos de la región, a fin de generar entre ellos una "cultura de recopilación de datos" $\mathrm{y}$, de esta forma, contribuir a que cada vez más hogares resguarden los datos de sus integrantes para, ante una eventualidad, brindar información más precisa para una mejor búsqueda, localización e identificación.

Aunque el acceso e impresión a la tarjeta de identificación personal es libre y gratuito en el sitio web y redes sociales de la Asociación, sus integrantes están conscientes de que la primera vía es llegar de manera directa a las personas, por lo que desde 2018 han llevado a cabo en varias escuelas de todos los niveles educativos, pláticas dirigidas a los padres de familia donde se les explica cuáles son los delitos de privación de la libertar a fin de que puedan distinguir entre uno y otro, y proceder así a presentar la denuncia respectiva; de la misma forma, documentan brevemente a los padres sobre la problemática de la violencia en la región y la importancia de contar con un adecuado registro de los datos, características y muestras de AND de ellos mismos y de todos los integrantes de sus familias, es decir, el llenado, y el permanente resguardo y actualización del tarjetón.

Las pláticas y distribución de tarjetones se han dirigido también a autoridades municipales de Poza Rica y otros ayuntamientos de la región, como en Papantla. ${ }^{19}$ La recepción ha sido variada y los compromisos por parte de la autoridades, poco claros. En ocasiones algunas autoridades han reconocido el esfuerzo de la Asociación y se han ofrecido a apoyar su trabajo a través de la organización de las conferencias e incluso de la impresión de los tarjetones, cuyos costos son elevados considerando el número de personas a las que se espera llegar en todo Poza Rica, municipios cercanos y, con el tiempo, un poco más allá. No obstante, también ha habido intenciones por parte de algunas autoridades (regidores) de politizar el trabajo de la Asociación, al condicionar el apoyo para la impresión y distribución del documento a que se inserten en el mismo el nombre del partido político al que pertenece el regidor, o a que distribuyan por personas de su partido estilo campaña política, situación que ha generado el distanciamiento del grupo respecto de alguna autoridades. Otro aspecto positivo del documento es que al reverso se incluyen algunas breves indicaciones sobre cómo proceder en caso de extravío, secuestro o desaparición forzada de algún familiar, y se plasman los números de las autoridades para emergencias o la presentación de denuncias, y también los datos de contacto de PPR 2040 (ANEXO A.2).

19 En 2018, el Ayuntamiento de Papantla donó 1000 tarjetones a PPR2040 por el apoyo brindado en su municipio. 
Aunque de manera inicial la distribución del documento se manejó como una medida preventiva para los delitos de privación de la libertad, con el paso de los meses PPR 2040 observó que en realidad no es tal, pues por sí mismo el registro y resguardo de los datos de ninguna manera contribuye a evitar o disminuir el riesgo de ser víctima de los mismos, ni de ningún otro tipo de delitos. No obstante, sí es posible afirmar que las pláticas y la distribución y llenado de los tarjetones ha resultado útil para contribuir a un proceso social de concientización del tema y de sensibilización para con quienes se ven afectados por el secuestro o desaparición de un familiar, ayudando a desestigmatizar a las víctimas y sus familias a quienes durante mucho tiempo la prensa oficial vinculó de manera generalizada y contundente con los grupos delictivos.

\section{LAS CARAS DE LA SIMULACIÓN: LAS RELACIONES DE LAS ORGANIZACIONES DE BÚSQUEDA DE DESAPARECIDOS CON LAS INSTITUCIONES DE PROCURACIÓN Y ADMINISTRACIÓN DE JUSTICIA EN VERACRUZ}

El Colectivo Familiares en Búsqueda María Herrera, al estar activo como tal a partir de junio de 2016, se ha visto afectado, como muchos de los veracruzanos, por los problemas políticos en torno a la cercanía que los titulares de la Fiscalía mantienen con el gobernador en turno. Así, además de enfrentarse a los bajos resultados de la fiscalía en torno la búsqueda, localización e identificación de personas reportadas como desaparecidas, así como a la inadecuada preservación de los cuerpos con los que se logra dar, los integrantes del Colectivo se han enfrentado también a la falta de sensibilidad de las autoridades para abordar el tema y de disponibilidad para atenderles, pero, sobre todo, a la desconfianza por las acusaciones que en torno a ellos han recaído al señalárseles como responsables precisamente del delito de desaparición forzada.

Como se señaló en el apartado correspondiente, el Colectivo se declara públicamente como tal frente al entonces último procurador y primer fiscal Luis Ángel Bravo Contreras, designado como tal - y en las dos ocasiones - por el ex gobernador Javier Duarte Ochoa. Es días después de esta declaración, en junio de 2016, que uno de los fundadores del Colectivo, José de Jesús Jiménez, es acribillado en la ciudad de Poza Rica y su esposa herida de gravedad. Dada la alternancia política que tomaría la gubernatura en diciembre de ese mismo año por el triunfo electoral de Miguel Ángel Yunes Linanes, Bravo Conteras renuncia al cargo para el que había sido designado apenas en agosto de 2015 para un periodo de 9 años. ${ }^{20}$ En estos escasos cinco meses de trato entre la Fiscalía y el Colectivo, el único logro para este fue que se le reconociera como tal y se iniciara un acercamiento directo con el órgano, pues aunque en grupo, los acercamientos anteriores habían sido muy forzados y, en ocasiones, a través de otros colectivos ya consolidados.

$\overline{20}$ Esto según la reforma constitucional promovida por Duarte en 2015. 
La derrota del PRI con el triunfo del gobernador panista Miguel Ángel Yunes Linares fue una luz para los colectivos de Veracruz, quienes habían recibido durante la campaña del entonces candidato distintas muestras de solidaridad y promesas de mantener el tema de los desaparecidos como prioritario en la agenda política del estado. El nombramiento del nuevo fiscal recayó de nueva cuenta en una persona cercana al nuevo gobernador a quien desde el principio se señaló como poco apta para el cargo dada su nula experiencia en materia de seguridad y procuración de justicia, el abogado Jorge Winckler González. Winckler ocupó la fiscalía a partir de diciembre de 2016 y bien pronto mostró que los desaparecidos y la atención a sus familiares no serían una prioridad en su gestión: negación de información, denostaciones, burlas, ${ }^{21}$ negativas para instalar las mesas de diálogo y para acudir a realizar las investigaciones a los sitios donde los colectivos reportaban la presencia de posibles fosas clandestinas, fueron algunas de las situaciones a las que las familias se enfrentaron, lo que se puso en perspectiva y evidencia a nivel nacional a partir de lo acontecido en el rancho La Gallera.

Un mes después de su nombramiento como Colectivo Familiares en Búsqueda María Herrera, a principios del siguiente año, en 2017, sus integrantes solicitaron al Fiscal intervenir para realizar una investigación en el rancho de cuatro hectáreas denominado La Gallera, ubicado en el municipio de Tiahuatlán. Los integrantes del Colectivo tuvieron conocimiento de que ese lugar estaba siendo utilizado por los grupos delictivos como cementerio clandestino por lo que solicitaron el apoyo de Winckler González con la esperanza de localizar a algunos de sus familiares en caso de que, en efecto, se realizaran algunos hallazgos. Después de varias solicitudes, el fiscal ordenó explorar el sitio el 02 de febrero para, posteriormente, negarse a revelar al público y a los integrantes del Colectivo los resultados de la investigación, dejándose además el sitio prácticamente abandonado, pues no se asignaron custodios. Como para acallar un poco las voces, más tarde reportaron que se habían localizado seis cuerpos; en principio, sólo el cuerpo de Enrique Chávez de 46 años de edad, desaparecido en noviembre de 2017, fue identificado y no gracias a las diligencias de los peritos, sino al trabajo del Colectivo, cuyos integrantes se dieron a la tarea de tomar fotografías de las prendas de ropa y tatuajes de los cuerpos localizados, y brindaron posteriormente acompañamiento a la familia para realizar las diligencias y exigir las pruebas de AND. Cabe señalar que, luego de haber sido identificado el cuerpo de Enrique, la fiscalía revictimizó a sus familiares negándose a entregarles el cuerpo de éste y reteniéndolo de manera injustificada por sesenta días.

Un mes luego de la visita de la fiscalía a La Gallera, en marzo de 2017, los integrantes del Colectivo realizaron una exploración en el mismo sitio con el apoyo de la Brigada Nacional de Búsqueda de Desaparecidos, localizando 22 fosas clandestinas con cientos de fragmentos de huesos humanos, así como prendas de vestir y zapatos de personas de distintas edades; reportaron también que

21 La falta de sensibilidad del fiscal en el tema ya no dejaría lugar a dudas cuando en junio de 2018, mediante redes sociales, diera a conocer orgullosamente su "regreso a las canchas" con su equipo al que llamó "Desaparecidos", ocupando la etiqueta \#EquipoFGEDesaparecidos". 
en el lugar fue hallado un horno supuestamente para la cocción de zacahulil (platillo típico de la región) con cenizas de dudosa procedencia, sugiriendo que en realidad dicho horno se estaba ocupando para incinerar cuerpos humanos. Aunque todos estos hallazgos se reportaron a la Fiscalía, entregándose las respectivas muestras, ni peritos, ni investigadores, ni custodios fueron enviados al lugar. A finales de abril, un mes más tarde, Miguel Ángel León Carmona, corresponsal del diario electrónico La Silla Rota, dio a conocer el vídeoreportaje titulado "El campo de exterminio que gobierno de Veracruz ocultó", en el que se muestran igualmente restos de huesos, prendas de vestir, vestigios de la presencia de la Fiscalía dos meses antes, así como testimonios de algunos de los integrantes del Colectivo, uno de los cuales describió el sitio como:

El lugar de cuatro hectáreas, (inaudible) era un cementerio, pero que no necesitábamos escarbar. Nos tropezábamos con los huesos y los restos humanos; se nos atravesaban mientras caminábamos. Así encontramos más de cien restos, muchos incinerados; un cráneo apenas a flor de piel de un niño o una niña de escasos diez u once años, no sabemos cuántos.

El videoreportaje de León Carmona fue transmitido en el noticiero nocturno de Ciro Gómez Leyva por Imagen Televisión, obligando a las autoridades federales a iniciar un diálogo con los integrantes del Colectivo y a atraer la investigación. Así, aprovechando el descontento con el gobierno panista en turno y su fiscal impuesto, el gobierno federal prí́sta se dio a la tarea de acercarse a algunos de los colectivos y, desde el mismo mes de abril de 2017, a través Roberto Campa Cifrián, entonces subsecretario de Derechos Humanos de la Secretaría de Gobernación, se iniciaría y sostendría el diálogo para iniciar las investigaciones en el predio de Tihuatlán.

No obstante, pese a que las negociaciones con gobierno federal a través de Campa Cifrián se iniciaran desde abril, éste aplazaba una y otra vez las investigaciones en la zona norte del Estado, empleando todo tipo de excusas para ello: desde el estado climático que le imposibilitaba viajar en avioneta, como la prioridad de atender a los damnificados por los sismos de septiembre de ese mismo año, lo que indica un aplazamiento de la visita de más de cinco meses. El activista Juan Carlos Trujillo Herrera, hijo de María Herrera, señalaba que: 'La situación de las prórrogas demuestra una incapacidad institucional del estado. Así como se solicitaron apoyos internacionales para la desgracia del sismo, en el tema de los desaparecidos deberían hacer lo mismo. Es la exigencia para el subsecretario Campa, que acepte esta incapacidad".

Al siguiente año, gobierno federal continuó brindando cierto tipo de atención y "ароyo" a los colectivos de Veracruz para "sus" labores de búsqueda; no obstante, dicho apoyo se mermó al iniciar el periodo electoral en abril de 2018, y se retiró por completo una vez conocidos los resultados de las elecciones federales y estatales de julio. Aunque desde el principio de su administración el nuevo gobernador morenista Cuitláhuac García Jiménez se ha mostrado discursivamente sensible al problema de los desaparecidos, la afrenta política sostenida con el 
fiscal Winckler fue la base para justificar de manera reiterada la falta de resultados durante el primer año de su gestión.

Luego de la toma de protesta de García Jiménez en diciembre de 2018, los esfuerzos del nuevo gobernador estuvieron focalizados a lograr la separación del fiscal, y los de éste, a mantenerse en el cargo, lo que trajo como consecuencia lógica que la desatención de la fiscalía (y del entonces nuevo gobierno) a los problemas de los desaparecidos y las demandas de los colectivos, continuara siendo materia denegada. La abierta confrontación entre el fiscal y el gobernador se prolongó por los siguientes catorce meses, hasta que a finales de marzo de 2020, recién iniciada la alerta sanitaria, la XLV Legislatura del Estado, donde el partido de Morena cuenta con mayoría, separó a Winkler de la fiscalía y designó a Verónica Hernández Giadáns como nueva fiscal. El análisis del desempeño de la nueva fiscal queda fuera de la periodicidad de este reporte; no obstante, se reconoce la necesidad de su estudio para mantener actualizado el balance de los avances y retrocesos en la materia.

\section{CONSIDERACIONES FINALES Y VETAS PARA FUTURAS INVESTIGACIONES}

Con el desarrollo de la investigación se buscó llevar a cabo un primer acercamiento al análisis de la problemática de los desaparecidos en el municipio de Poza de Hidalgo, Veracruz, considerando, la falta de resultados de las tres últimas administraciones gubernamentales (hasta diciembre de 2019) estatales para brindar respuestas a los familiares de los desaparecidos y contener el incremento de la violencia, así como las estrategias y resultados de las familias a través de su trabajo como colectivos de búsqueda, en particular, del Colectivo María Herrera Familiares en Búsqueda.

Quienes de uno u otro modo están atentos a los problemas de inseguridad e impunidad en el estado, verán que lo aquí narrado para Poza Rica bien se puede considerar la porción de un fractal mayor que se despliega por todo el territorio veracruzano; quienes se inician en estos temas, por su parte, podrán ubicar en el contexto aquí expuesto un referente para introducirse en la comprensión de estos temas a nivel subnacional.

Varias conclusiones se pueden extraer de lo expuesto en este reporte; sin embargo, el punto que de momento se ha preferido destacar aquí, es el rápido proceso de organización y maduración del Colectivo María Herrera, cuyos integrantes en menos de un lustro y con muy escasos recursos, han mostrado una extraordinaria capacidad para trabajar con, contra o pese a las autoridades de los tres niveles de gobierno; trabajo en el que se han mantenido constantes, lo que les ha permitido alcanzar un relativo éxito en lo que respecta a la localización de personas desaparecidas y la identificación de cuerpos. Los aspectos anteriores, junto con el trabajo de preparación en materia forense, son las actividades que suelen destacase más de estos grupos de trabajo. El trabajo de los colectivos, como muestra el caso específico del María Herrera, a través de la caracterización de la 
actividades que aquí se propone, evidencia que su labor es mucho más amplia e incluye aspectos como el registro y documentación de casos, asesorar a las familias para la presentación de la denuncia y seguimiento de casos, brindar apoyo y acompañamiento solidario de tipo psicosocial para el autocuidado, esforzarse por mantener vigente el tema de los desaparecidos dentro de la agenda pública, y brindar apoyo a los menores, hijos e hijas de personas desaparecidas

Ahora bien, el contexto de la violencia y las desapariciones forzadas en la región norte del estado, en particular en el municipio de Poza Rica de Hidalgo, ofrece una lectura bastante similar a la que se puede hacer de todo Veracruz, como se ha señalado, pero también en cierta medida, a la que prevalece a nivel nacional. Sobresalen aquí dos cuestiones; primero, la elevada tasa de impunidad que predomina a favor de los responsables de estos hechos delictivos; esto debido no sólo a la cifra negra o bajo número de denuncias por parte de las familias afectadas, sino también a la falta de sensibilidad y compromiso de las autoridades para hacer frente al problema; lo que no es de extrañar dado que debe recordarse que este tipo de delito apunta necesariamente, por acción, omisión o aquiescencia, a los servidores públicos y, en su caso, a su colusión con integrantes de los grupos delictivos. El segundo punto que sobresale aquí es el uso y abuso que los gobiernos en turno hacen de las instituciones de seguridad, y de las instituciones de procuración e impartición de justicia, pues periodo a periodo, tales instituciones son empleadas con fines más bien políticos; esta situación es observable en prácticamente cualquier contexto subnacional de México, aunque sobresale el caso de Veracruz, como se expuso en el último apartado, lo que exige en análisis de los cambios que han afectado la integración del máximo tribunal del Veracruz y de la fiscalía general del estado. Desafortunadamente, esto implica reconocer que no importa cuáles sean los avances de los colectivos, la compleja problemática continuará si las capacidades del Estado no se ensanchan y empieza a dar respuestas eficientes en materia prevención del delito, de persecución de los delitos, de sanción de los responsables $\mathrm{y}$, desde luego, en todo lo señalado que atañe a lo que es la búsqueda, localización e identificación de personas desaparecidas, así como de resguardo y preservación de cuerpos.

\section{BIBLIOGRAFÍA}

Asociación Nacional de Alcaldes, y otros. 2018. Atlas del riesgo político-electoral en México. http://www.atlasriesgoelectoral.mx/Archivos-PDF/Reporte.pdf

Artículo 19. Periodistas asesinados en México en relación con su labor informativa. https://articulo19.org/periodistasasesinados/

Centro de Estudios Sociales y de Opinión Pública de la Cámara de Diputados. 2018. Las ciudades mexicanas, el perfil de la población y las escalas de prosperidad.

DE ALBA, José Ignacio. 11, 09, 2016. Poza Rica, Veracruz, la ciudad que pasó de la abundancia con el oro negro a vivir una crisis. Animal Político. https:// www.animalpolitico.com/2016/09/poza-rica-veracruz-petroleo-pemex/comment-page-1/ 
DÍAZ, Gloria Leticia. 14, 06, 2019. Desde 2006, han sido asesinados 46 defensores de derechos humanos: CNDH. Proceso. https:/www.proceso.com. $\mathrm{mx} / 588311 /$ desde-2006-han-sido-asesinados-46-defensores-de-derechoshumanos-cndh

El Heraldo de Poza Rica. 11, 06, 2019. Colectivos le hacen la chamba a fiscalía*** Localizan 11 personas en condición de calle. El Heraldo de Poza Rica. https:// issuu.com/poza_acme/docs/el_heraldo_de_poza_rica_11_de_junio_9200d1a3b192fd

El Piñero. 29, 03, 2018. Reportan secuestro de Ex Fiscal de Poza Rica Julio Roberto Christfield Torres. https:/www.elpinero.mx/reportan-secuestro-del-exfiscal-de-poza-rica-julio-roberto-christfield-torres/

ESCAMILLA, Edgar. 06, 09, 2019. Delincuentes, más astutos que policías, según reconoce el alcalde de Poza Rica: se van para allá y se vienen para acá. $L a$ Jornada Veracruz. http://www.jornadaveracruz.com.mx/Post.aspx?id=190906 075324680

La Verdad. 01, 06, 2019. Los Zetas lanzan amenazas para los grupos antagónicos en Poza Rica, Veracruz. https://laverdadnoticias.com/crimen/VIDEO-LosZetas-lanzan-amenazas-para-los-grupos-antagonicos-en-Poza-Rica-Veracruz-20190601-0028.html

LE CLERCQ ORTEGA, Juan Antonio y Gerardo Rodríguez Sánchez Lara (Coordonadores). 2018. Índice Global de Impunidad México IGI MEX 2018. MUDALP. https:/www.udlap.mx/igimex/assets/files/2018/igimex2018_ESP.pdf

LEÓN CARMONA, Miguel Ángel. 09, 09, 2019. Veracruz, un estado letal para periodistas. La silla rota Veracruz, https://veracruz.lasillarota.com/estados/ veracruz-un-estado-letal-para-periodistas-violencia-mexico-periodismo-reporteros/316211

14, 11, 2017. Encuentran indicios de restos en fosa La Gallera. La Silla Rota. https://veracruz.lasillarota.com/estados/encuentran-indicios-de-restos-en-fosala-gallera-veracruz-la-gallera-restos/188473

LÓPEZ, Lidia. 11, 03, 2017. Refuerzan operativo en PR ante incrementode delitos. Al Calor Político. https://www.alcalorpolitico.com/informacion/refuerzanoperativo-en-poza-rica-ante-incremento-de-delitos-regresan-retenes-de-revision-228719.html

MACÍAS ZAPATA, Gabriel Aarón. 2018. La incursión del crimen organizado en el gremio de taxistas. El caso de la Zona Hotelera de Cancún. La crisis de seguridad y violencia en México. Causas, efectos y dimensiones del problema. Carlos Antonio Flores Pérez, Coordinador.

Noreste. 25, 05, 2018. La Gallera, un panteón; localizan más restos humanos, en Tihuatlán. Diario Noreste. http://www.noreste.net/noticia/la-gallera-un-panteon-localizan-mas-restos-humanos-en-tihuatlan/

PILLADO, Ángeles. 07, 06, 2018. FGE estrena equipo de futbol "Desaparecidos" y desata polémica. SPD Noticias Veracruz. https://www.sdpnoticias.com/local/ veracruz/desaparecidos-estrena-futbol-equipo-fge.html 
Proceso. 01, 03, 2016. Jóvenes desaparecidos en Tierra Blanca fueron "quemados y molidos": Campa. Proceso. https://www.proceso.com.mx/431906/jovenesdesaparecidos-en-tierra-blanca-fueron-quemados-y-molidos-campa

Secretaría de Gobernación. 2018. Sistema Urbano Nacional 2018. https://www. gob.mx/cms/uploads/attachment/file/400771/SUN_2018.pdf

Sin Embargo. 25, 06, 2019. Poza Rica pudo ser Houston con tanto petróleo. No fue. Quedan pobreza, contaminación, olvido. SinEmbargo. https://www.sinembargo.mx/25-06-2019/3602034

TRUJILlO BÁEZ, Norma. 30, 01, 2019. En Poza Rica, 30 jóvenes han sido levantados en zona que reúne bares. La Jornada Veracruz. http://jornadaveracruz.com.mx/Post.aspx?id=190130_121032_603

Vanguardia Política. 02, 01, 2020. Policía incapaz de combatir el delito. https:// www.vanguardiaveracruz.mx/policia-incapaz-de-combatir-el-delito/

ZAVALA, Juan Carlos. 24,04, 2019. Estado, el primero en homicidio de políticos. El Universal. 2019. https://www.eluniversal.com.mx/estados/estado-el-primero-en-homicidio-de-politicos 


\section{Anexo A. 1 Tarjeta de Identificación Personal de Proyecto Poza Rica}

2040. Anverso

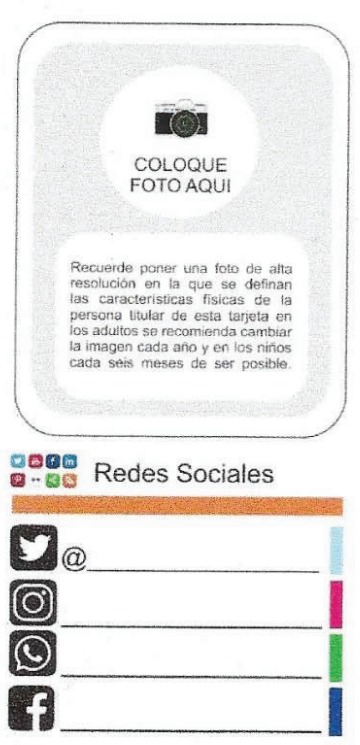

Información Médica

Diabético (a) si $\square$ No $\square$ Hipertenso (a) si $\square$ № $\square$ Asmático (a) si $\square$ No $\square$ Alzhaimer si $\square$ No $\square$ Sangre Tipo: Alergias:

\section{Información Personal}

Nombre:

Dirección:

Nacimiento: $\frac{1}{D D} \frac{1}{\mathrm{MM}} \frac{1}{\mathrm{M}}$ Apodo:

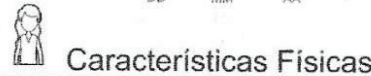

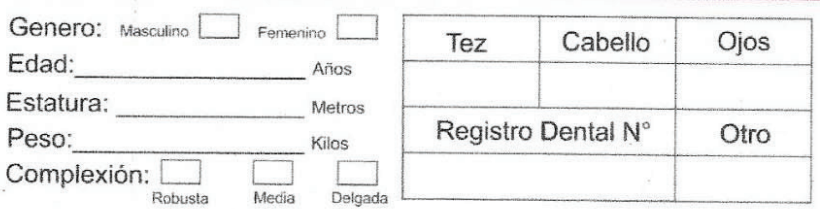

\section{Características Distintivas}

Mi familiar en el momento de su desaparición o extravio se le puede

distinguir por sus: (Describa Brevemente)

Aretes:

Anteojos:

Braquets:

Tatuajes:

Lunares:

Pupilentes:

Marcas:

Ropa:

Calzado:

Características Comparativas (Muestras que contengan el A.D.N. como cabello o uñas y huellas dactiares)

Introduzca en ura Boisa Cabeilo

o Pedazos de Uña, pliegue y coloque aqui

Las muestras que contengan ADN, asi como, las huellas dactilares son fundamentales para la búsqueda, registro y localización con o sin vida de personas desaparecidas, raptadas, secuestradas, extraviadas o sustraidas

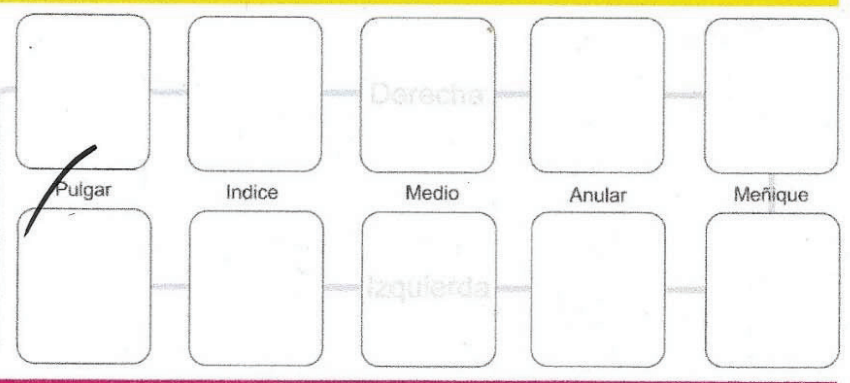

En caso de Localización llamar a:

Telefono (s): 
Anexo A. 2 Tarjeta de Identificación Personal de Proyecto Poza Rica 2040. Reverso
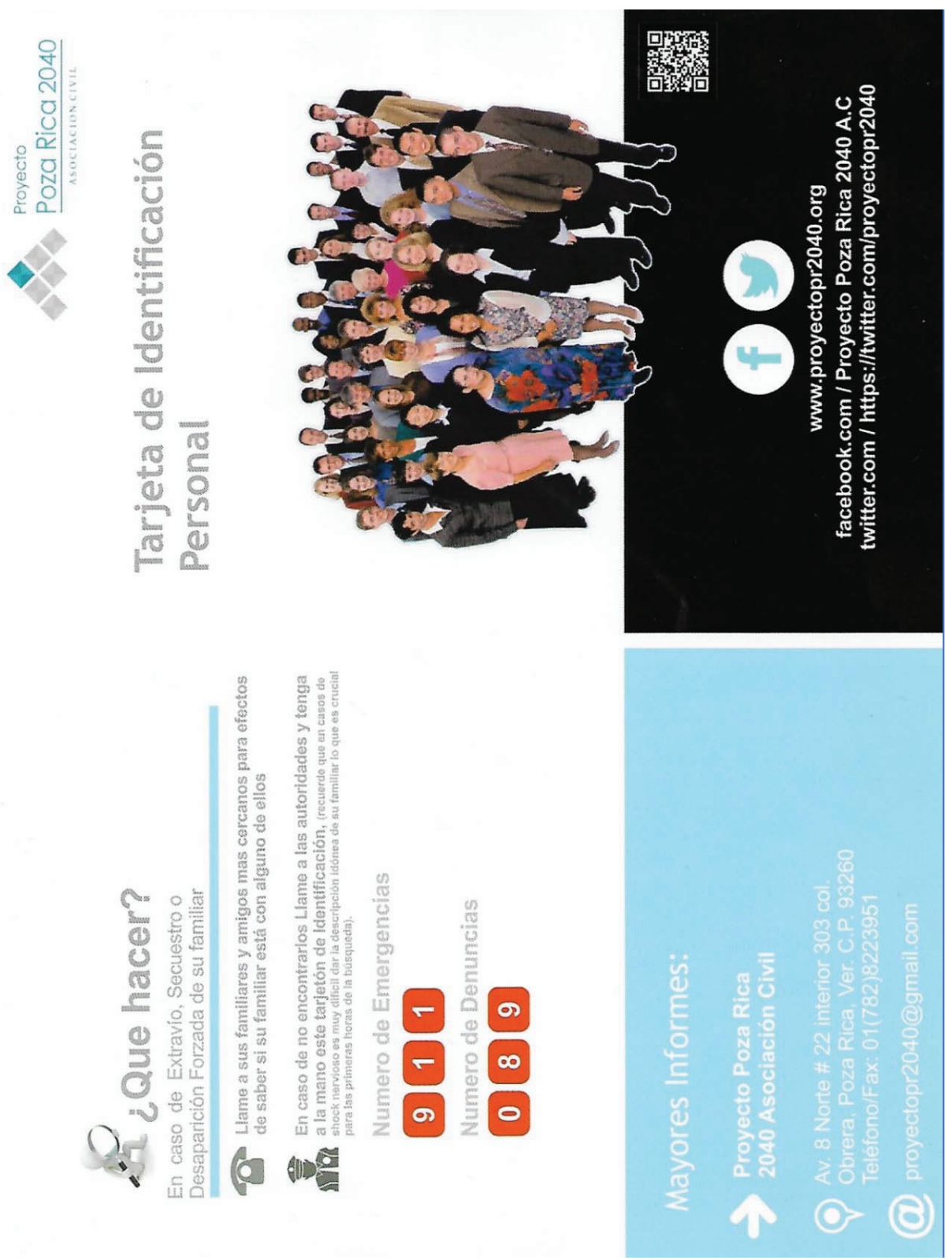